\title{
4
}

\section{UMA CRÍTICA MARXISTA À ECONOMIA POLÍTICA DA CONTRARREFORMA PREVIDENCIÁRIA}

\author{
A marxist critique of the political economy of pensions \\ counter-reform
}

Thais Soares Caramuru*

(cc) BY-NC

\begin{abstract}
RESUMO
Diante da ofensiva capitalista contra as condições de acesso à proteção previdenciária pela classe trabalhadora brasileira torna-se imperioso o uso do arcabouço teórico-metodológico marxiano para revelar a verdadeira natureza do processo em curso. Assim, este artigo teve como objetivo geral fornecer elementos para uma crítica marxista à economia política da contrarreforma previdenciária e, como objetivo específico, pretendeu desvendar o caráter liberal e conservador que permeia os pressupostos, argumentos e algumas das propostas da marcha contrarreformista. Em última instância, foi possível identificar que todo o movimento está revestido por uma visão de mundo burguesa propagada especialmente pelo Banco Mundial e que busca potencializar a subsunção do trabalho ao capital.
\end{abstract}

\section{PALAVRAS-CHAVE}

ontrarreforma. Previdência Social. Crítica da economia política.

\begin{abstract}
In sight of the capitalist offensive against the Brazilian working class' conditions to access the pensions system the use of the Marxian theoretical and methodological framework to reveal the true nature of the process is fundamental. That said, this article had the general aimed of providing contributions to a critique of the political economy of the social pension counter-reform and, as a specific purpose, it intended to expose the liberal and conservative character that compose the axioms, the arguments and some of the proposals of the counter-reform march.

* Economista. Mestre em Política Social. Analista Técnica de Políticas Sociais da Carreira de Desenvolvimento de Políticas Sociais no Ministério da Educação. Esplanada dos Ministérios, Bloco L, Edifício Sede, CEP 70047-900. E-mail: <tcaramuru@gmail.com>.
\end{abstract}




\section{temporalis}

Ultimately, it was possible to visualize that the entire procedure is perceived by a bourgeoisie conception of the world, propelled mainly by the World Bank, that targets the reinforcement of the subrogation of labor to capital.

\section{KEYWORDS}

Counter-reform. Social Pension. Critique of the political economy.

Submetido em: $x x / x / 2017$

Aceito em: $x x / x x / 2017$

\section{INTRODUÇÃO}

Os tempos correntes caracterizam-se por uma violenta ofensiva capitalista contra as condições de vida, trabalho e proteção social da classe trabalhadora brasileira. No caso da Seguridade Social, mais precisamente da Previdência, o ataque burguês visa à imposição de uma drástica restrição do acesso a esta política social por parte de amplos contingentes de trabalhadores. Essa desalentadora quadra histórica impõe a pesquisadores que estão a serviço da massa oprimida debruçar-se teoricamente sobre a atual conjuntura e descortinar seu caráter reacionário.

Nessa perspectiva, este artigo tem como objetivo geral fornecer elementos para uma crítica marxista à economia política da contrarreforma previdenciária e, como objetivo específico, desvendar o caráter liberal e conservador que permeia os pressupostos, os argumentos legitimadores e algumas das propostas que compõem a marcha contrarreformista que visa ao desmonte dos regimes públicos de Previdência. A hipótese geral que sustenta a análise é a de que o processo em curso está revestido por uma visão de mundo burguesa que, em sua essência, busca potencializar a subsunção do trabalho ao capital. Quanto à perspectiva teórico-metodológica, a natureza do objeto exige o uso da dialética-materialista e o arcabouço categorial fornecido pela teoria social crítica marxiana.

A exposição configura-se por três seções primárias, além desta introdução e das considerações finais: a primeira está destinada à abordagem dos aspectos gerais que a economia política da contrarreforma previdenciária; a segunda visa à abordagem da concepção burguesa do sistema de seguridade social; e a terceira problematiza a reciprocidade entre a ofensiva à Previdência e a ética do trabalho assalariado. As referências complementam o trabalho. 


\section{ASPECTOS CONSTITUTIVOS GERAIS DA ECONOMIA POLÍTICA DA CONTRARREFORMA}

Em primeiro lugar, se faz relevante repudiar o uso da palavra reforma para qualificar o movimento de ofensiva do capital, pois esta palavra teve uma conotação histórica claramente progressista, vinculada às lutas de classes (COUTINHO, 2010). Assim sendo, no contexto contemporâneo de crise estrutural do capital, o ataque à proteção social no Brasil constitui-se em um processo reacionário que Behring (2008) oportunamente qualifica como contrarreforma.

A ofensiva à Previdência Social atingiu uma etapa dramática com a apresentação, por um governo ilegítimo, da Proposta de Emenda à Constituição $(P E C) n^{\circ}$ 287/2016, a qual visa à restrição das regras de acesso e à redução da magnitude monetária dos benefícios previdenciários de amplos segmentos da classe trabalhadora brasileira: aqueles que atuam na iniciativa privada; autônomos; servidores públicos civis de todas as esferas'; trabalhadores rurais; as mulheres trabalhadoras em geral; deficientes; idosos de baixa renda; professores da educação básica; trabalhadores que atuam em atividades insalubres. Caso aprovadas, as regras impostas por esta PEC terão o condão de ampliar o contingente de trabalhadores idosos sem proteção e que serão expulsos do sistema previdenciário “[...] por não terem capacidade contributiva, por não terem saúde para continuar no trabalho e por saberem que é inútil contribuir para algo inatingível ou apenas atingível quando restar quase nada de vida com alguma dignidade" (FAGNANI, 2017, p. 9).

O caráter drástico da PEC $n^{\circ}$ 287/2016, no entanto, não deve obscurecer o fato de que a contrarreforma dos regimes públicos de previdência social instituídos pela Constituição Federal (CF) de 1988 é um processo em marcha desde meados da década de 1990 e executado por diversos governos, consolidando um movimento que Granemann (2016) apropriadamente denomina de "divisão técnica do trabalho"2.

A funcionalidade da contrarreforma da Previdência à acumulação capitalista pode ser atribuída à busca dos seguintes objetivos: liberar

1 Os militares foram convenientemente protegidos da ofensiva contrarreformista.

2 Trata-se das Emendas Constitucionais n²0/1998 e n 41/2003. 
recursos do fundo público para aplicação direta na reprodução do capital; impulsionar a adesão de parcelas da classe trabalhadora à compra de produtos vendidos pela chamada "previdência privada"; ampliar o tempo de disponibilização de diversos setores da classe trabalhadora à subsunção ao capital. (GRANEMANN, 2016; BOSCHETTI, 2016). Postas estas questões, cumpre qualificar o que se considera a economia política da contrarrefoma previdenciária.

De acordo com Lowy (2015), o estudo das ciências sociais é permeado por ideologias e concepções das classes, as quais configuram-se como visões sociais de mundo e referem-se a "[...] todos aqueles conjuntos estruturados de valores, representações, ideias e orientações cognitivas [...] de classes sociais determinadas" (LOWY, 2015, p. 21). No que tange à economia política, na perspectiva de Marx (1983), esta é uma ciência essencialmente burguesa cujo valor científico foi deteriorado quando a burguesia deixou de ser uma classe revolucionária e atingiu a posição de classe dominante, de modo que, à medida que a ordem capitalista se desenvolveu e o conflito capital-trabalho passou a predominar as relações sociais, a economia política burguesa converteu-se em apologética a serviço da ordem estabelecida, pois, "[...] já não se tratava de saber se este ou aquele teorema era ou não verdadeiro, mas se, para o capital, ele era útil ou prejudicial, cômodo ou incômodo, subversivo ou não" (MARX, 1983, p. 17).

Pois bem, à luz dessas percepções, o que aqui se denomina economia política da contrarreforma previdenciária é o processo conformado pelos seguintes fundamentos: a adoção de pressupostos revestidos pela visão social de mundo burguesa; o uso de argumentos legitimadores desprovidos de valor científico; a apresentação de propostas que visam à manutenção da ordem estabelecida, com a potencialização da subordinação do trabalho ao capital. Parte-se, então, à abordagem de dois elementos gerais que constituem esse processo: o economista vulgar propagador da contrarreforma previdenciária e a naturalização do processo de envelhecimento da classe trabalhadora.

A respeito do primeiro elemento, no âmbito da crítica marxiana à economia política clássica, Lowy (2015) identifica que o autor d'O Capital faz uma clara distinção entre dois tipos de economistas 
burgueses: o primeiro refere-se aos economistas clássicos, que engloba, por exemplo, as obras de Adam Smith e David Ricardo, as quais tinham elevado valor científico haja vista haver em seus escritos uma real intenção de conhecer a realidade, chegando, inclusive, a desenvolver a teoria do valor que depois seria aprofundada por Marx (1983); o segundo tipo são os economistas vulgares, formados por autores como Jean-Baptiste Say e Thomas Malthus, cujas obras destinam-se fundamentalmente à apologia superficial do capitalismo, de modo que estes eram "[...] indivíduos que gritavam em defesa da propriedade privada, servidores, agentes servis da classe dominante e, por isso, sua obra tinha muito pouco valor científico" (LOWY, 2015, p. 122).

Com base nessa diferenciação marxiana em relação às duas espécies de economistas burgueses, afirma-se, aqui, que a economia política da contrarreforma da Previdência Social tem muitos economistas vulgares, mas um, em especial, merece destaque: o Banco Mundial (BM). Trata-se de uma agência que atua a serviço da manutenção da ordem capitalista internacional cuja criação remete ao ano de 1944, em Bretton Woods. Na área das políticas sociais, a literatura crítica denuncia que esta instituição imperialista atua ostensivamente na propagação de orientações de caráter neoliberal, com destaque para a apologia aos programas de transferência de renda condicionada e a contrarreforma dos sistemas educacionais e de saúde, especialmente - mas não restritivamente - em países periféricos (PEREIRA, 2014).

No caso dos regimes públicos de Previdência Social, este economista vulgar acumula documentos repletos de fraseologias burguesas que têm como objetivo precípuo propagar a redução da abrangência dos sistemas públicos e o estímulo à adesão a "planos" privados ao redor do mundo. O paradigma desta orientação está constante no documento denominado Envejecimiento Sin Crisis, publicado em 1994, e que tem como epicentro a proposição de um sistema de três pilares 3 para orientar a estrutura dos benefícios previdenciários dos trabalhadores: o primeiro pilar seria constituído por uma parcela obrigatória administrada pelo setor público e que teria magnitude

3 Uma sólida análise marxista do sistema de pilares pode ser encontrada em Granemann (2006, p. 107-128). 
monetária mínima; o segundo pilar corresponderia a uma parcela obrigatória administrada pelo setor privado e que seria equivalente aos fundos de pensão ocupacionais; o terceiro pilar seria de caráter voluntário e equivale aos planos de "previdência privada" vendidos pelos bancos (BANCO MUNDIAL, 1994).

De acordo com a análise de Granemann (2006), as formulações do BM se convertem em “[...] argumentos 'teóricos' sustentáculos das contrarreformas e dos debates travados em torno delas" (GRANEMANN, 2006, p. 105). Isto se justifica porque o elemento primordial para a implementação deste sistema de pilares é a restrição das regras de acesso e e a diminuição da magnitude dos benefícios providos pelos regimes públicos de previdência, sendo, portanto, sob os marcos desta orientação que a contrarreforma dos sistemas públicos se propagou por países do centro e da periferia.

A atuação do BM como economista vulgar da contrarreforma previdenciária, contudo, não se restringe ao supramencionado documento da década de 1990, de maneira que, ao longo dos anos, as publicações deste intelectual orgânico do capital passaram a "analisar" os sistemas previdenciários com publicações específicas por países. A respeito do sistema de proteção social brasileiro, a publicação intitulada Growing Old in an Older Brazil ${ }^{4}$, de 2011, apresenta orientações e concepções que podem ser diretamente relacionadas ao caráter reacionário das propostas constantes na PEC n² 287/2016 (WORLD BANK, 2011).

Nessa perspectiva, fica estabelecido um dos aspectos gerais que constituem a economia política da contrarreforma previdenciária, qual seja, o fato de que uma agência burguesa propagadora dos interesses do capital exerce o papel de um economista vulgar cujas concepções de mundo, argumentos legitimadores e propostas explicitam a essência conservadora do processo em curso, conforme será delineado mais adiante.

O outro elemento geral constitutivo da economia política da contrarreforma previdenciária que aqui merece ser abordado

4 Todas as citações do referido documento são traduções próprias do inglês, o que não será mais mencionado por questão de espaço. 
é a naturalização do processo de envelhecimento da classe trabalhadora por parte do governo federal e do economista vulgar.

De modo geral, os apologistas da contrarreforma fazem uso de dois argumentos legitimadores primordiais: o chamado déficit e o envelhecimento. Enquanto o primeiro já foi amplamente desconstruído por pesquisadores sérios como Salvador (2010), o segundo permanece à margem das análises críticas das propostas contrarreformistas. No entanto, a questão relacionada ao envelhecimento populacional é fundamental para a análise crítica da contrarreforma, pois sobre ela sustentam-se tanto a apologética do $\mathrm{BM}^{5}$ (1994; 2011) quanto os argumentos utilizados pelo governo federal na exposição de motivos da $P E C n^{\circ} 287 / 2016$, que afirma que "[...] as mudanças demográficas impõem um grande desafio para o futuro da sociedade e, de modo particular, para a previdência social" (BRASIL, 2016, p. 14). Para ilustrar este "gigantesco desafio", faz-se uso de gráficos, pirâmides, ilustrações e projeções exuberantes acerca do aumento da expectativa de sobrevida da população, chegando o governo federal a estimar que a população com 65 anos ou mais crescerá 262,7\% entre 2013 e 2060 (BRASIL, 2016).

O debate acerca das interrelações entre o comportamento das variáveis populacionais e os fenômenos sociais é bastante antigo na economia política clássica e sua maior expressão foi a teoria da população de Thomas Malthus ${ }^{6}$, a qual fundava-se no pressuposto de que a causa da existência da pobreza, da miséria e da indingência era o superpovoamento da terra. Ou seja, a análise deste autor, objeto de crítica por Marx (1983), desconsiderava as condições materiais e as relações sociais decorrentes da forma como a sociedade capitalista se reproduz. Esse mesmo equívoco é cometido pelos economistas vulgares que fazem uso das extraodinárias projeções de elevação da expectativa de vida da população para legitimar a contrarreforma.

Em uma perspectiva marxista, a questão do aumento da longevidade da classe trabalhadora precisa ser abordada à luz da perspectiva da totalidade do ser social, isto é, da forma como esta classe está

5 Vide os títulos dos documentos anteriormente citados. 6 Um economista vulgar, na concepção de Marx (1983). 
inserida no modo de funcionamento da produção capitalista. Marx (1983), ao abordar as disputas inter-classes no processo de regulamentação da jornada de trabalho na Inglaterra, afirma que “[...] o capital não tem, por isso, a menor consideração pela saúde e duração de vida do trabalhador, a não ser quando é coagido pela sociedade a ter consideração" (MARX, 1983, p. 215).

Desta feita, é possível inferir a seguinte circunstância: a essência exploratória do capitalismo sempre se constituiu em uma ameaça a qualquer possibilidade de o trabalhador adquirir longevidade ao longo de sua vida, haja vista que a força de trabalho "[...] é roubada de suas condições normais, morais e físicas, de desenvolvimento e atividade" (MARX, 1983, p. 212).

Nesse sentido, é possível conceber que o fato de a classe trabalhadora, nas condições do capitalismo periférico brasileiro, ter conseguido, ao longo da segunda metade do século XX, alcançar um determinado grau de prolongamento de sua vida, não foi um elemento movido por forças naturais mecânicas como tentam propagar os economistas vulgares da contrarreforma. Trata-se, ao contrário, de uma construção social, diretamente relacionada às condições de vida e proteção contra a exploração do trabalho, pois, conforme afirma Paiva (2014, p. 34), “[...] no âmbito das sociedades de modo de produção capitalista, a velhice é também uma produção social".

Ante todas essas considerações, o uso, por parte dos contrarreformistas, de "projeções draconianas" (FAGNANI, 2017) acerca do exponencial aumento da sobrevida da classe trabalhadora brasileira para o ano de 2060, exige a colocação da seguinte pergunta: nos marcos da contrarreforma trabalhista, que elevará o grau de exploração da massa trabalhadora do país, do desmantelamento do Sistema de Seguridade Social, da imposição da EC nº 95/2016 que reduzirá, em termos reais, os gastos sociais nos próximos vinte anos, quais são as efetivas perspectivas da massa trabalhadora alcançar elevados patamares de prolongamento da vida? É a este grande desafio que os economistas vulgares deveriam debruçar-se.

Delineados os aspectos constitutivos gerais da economia política da contrarreforma previdenciária, parte-se para a problematização da concepção burguesa do Sistema de Seguridade Social. 


\section{A CONCEPÇÃO BURGUESA DO SISTEMA DE SEGURIDADE SOCIAL}

O Sistema de Seguridade Social concebido no âmbito da CF de 1988 constituiu-se em arcabouço inovador na forma de estruturação da proteção social no Brasil, haja vista prever a articulação entre as políticas de previdência, saúde e assistência social, regido pelos princípios da universalidade e da diversidade das fontes de financiamento (BEHRING; BOSCHETTI, 2011; SALVADOR, 2010). Este sistema, no entanto, também estava dotado de limitações, pois enquanto a utilização dos serviços de saúde foi estabelecida como universal aos trabalhadores, o acesso aos benefícios previdenciários teve como condicionante fundamental as contribuições diretas prévias dos trabalhadores, o seja, o que Boschetti (2016) denomina lógica do seguro contributivo.

Todas essas particularidades do referido sistema - e o próprio fato de a previdência fazer parte dele - são deliberadamente ignorados pelo economista vulgar Banco Mundial (WORD BANK, 2011), pelo governo federal (BRASIL, 2016) e por outros apologistas da contrarreforma, de maneira que a concepção burguesa acerca do Sistema de Seguridade Social destaca-se pelos seguintes aspectos: abordagem da temática relacionada ao "equilíbrio" do sistema apenas pela perspectiva das despesas; concepção liberal da figura do trabalhador contribuinte direto como um indivíduo racional maximizador de seu bem-estar; pressuposto de que o sistema é generoso.

O primeiro aspecto constitutivo da concepção burguesa da Seguridade Social é a abordagem da temática relacionada à busca do "equilíbrio" do sistema apenas pela perspectiva das despesas, o que leva os economistas vulgares a restringirem sua abordagem apenas à imposição de rígidas regras de acesso e à redução da dimensão monetária dos benefícios, desconsiderando a potencialidade de arrecadação das múltiplas receitas do sistema. $\mathrm{Na}$ apologética do economista vulgar esta dimensão da ofensiva recebe a denominação de "custos fiscais do envelhecimento" (WORLD BANK, 2011).

Conforme já foi dito, um dos princípios de tal sistema é o da diversidade da base de financiamento, o que significa que a previdência não precisaria ser financiada apenas pelas contribuições 
diretas dos trabalhadores e empregadores e que uma série de outras contribuições também existem, tais como aquelas relacionadas ao lucro e ao faturamento. (BEHRING; BOSCHETTI, 2011; SALVADOR, 2010).

Nessa perspectiva, é relevante apontar que, no âmbito da arrecadação do Sistema, as verdadeiras distorções existentes são aquelas que beneficiam explicitamente o capital, as quais são apontadas por Salvador (2010), tais como: o surrupio de recursos da Seguridade por meio da Desvinculação das Receitas da União; a famigerada política de renúncias fiscais; uma legislação tributária que favorece a sonegação; o uso de recursos da Seguridade para pagar despesas fiscais; a política de parcelamento de débitos tributários, inclusive previdenciários, a grandes empresas, que materializam-se sob a forma de verdadeiras moratórias ao capital. Apesar dessas benesses à classe dominante, a robustez do sistema é corroborada pelas análises anuais realizadas pela Associação Nacional dos Auditores Fiscais da Receita Federal do Brasil (ASSOCIAÇÃO NACIONAL DOS AUDITORES FISCAIS DA RECEITA FEDERAL DO BRASIL, 2016).

Em realidade, esta dimensão fiscalista da contrarreforma oculta a disputa que está em jogo pelo fundo público, pois, “[...] as elites financeiras jamais aceitaram que o movimento social dos anos 1970 e 1980 introduzisse na Constituição de 1988 o capítulo sobre a seguridade social, que captura cerca de 10\% do PIB" (FAGNANI, 2016, p. 88).

Para além desses aspectos, a visão social de mundo burguesa em relação à Seguridade se expressa de modo peculiar a partir da concepção liberal do trabalhador contribuinte como um indivíduo racional maximizador de seu bem-estar. A crítica a esta dimensão da concepção contrarreformista exige esclarecimentos acerca da doutrina do liberalismo econômico clássico e sua relevância ideológica no estabelecimento das relações sociais capitalistas.

Nos marcos da economia política clássica, Adam Smith e John Stuart Mill são os principais expoentes dessa doutrina e sua principal funcionalidade ideológica foi legitimar e naturalizar a ascensão da burguesia e a consolidação das relações de classe tipicamente capitalistas, pois sem a liberdade não haveria como 
lograr o poder econômico e a propriedade. Neste âmbito insere-se a famosa concepção smithiana da mão invisível, segundo a qual a propensão à troca é intrínseca à natureza humana e que pressupõe que cada indivíduo agindo de acordo com seus próprios interesses promoveria a riqueza e o progresso das nações (PAULANI, 1999).

Quando os economistas vulgares da contrarreforma pressupõem que a contribuição direta à previdência é resultante de uma mera decisão ou escolha dos trabalhadores, ocorre uma naturalização da forma de organização social em que estes estão inseridos, bem como da própria dinâmica de funcionamento da previdência como política social intrinsecamente relacionada às relações de produção capitalistas (SILVA, 2012). Em outras palavras, esta percepção ignora que, no Brasil, a contribuição previdenciária direta está intrinsecamente relacionada à capacidade contributiva por longo período de tempo, o que, por sua vez, relaciona-se com o grau de formalização do vínculo empregatício e com o patamar salarial do trabalhador. Em última análise, a contribuição previdenciária depende menos da própria vontade do trabalhador e mais do caráter de sua inserção na produção material, pois, como afirmou Marx (2008, 47), “[...] na produção social da própria existência, os homens entram em relações determinadas, necessárias, independentes de sua vontade; essas relações de produção correspondem a um grau determinado de desenvolvimento de suas forças produtivas materiais".

Dados da Pesquisa Nacional por Amostra de Domicílios (PNAD) revelam que, em 2015, 62\% da População Economicamente Ativa Ocupada contribuía para institutos de previdência (INSTITUTO BRASILEIRO DE GEOGRAFIA E ESTATÍSTICA, 2015). A parcela da massa trabalhadora que não é coberta por tal percentual não está nesta condição por simples escolha, mas sim em decorrência de sua (não) inserção produtiva nesta sociedade periférica. Portanto, a capacidade de abrangência da cobertura previdenciária em um país como o Brasil, com um sistema baseado na lógica do seguro contributivo e que não consolidou o Estado Social ampliado (BOSCHETTI, 2016) está diretamente relacionada à estrutura do mercado de trabalho e à forma de inserção material da massa trabalhadora neste contexto. 
Outro aspecto a ser apontado acerca da concepção burguesa do sistema é a fraseologia de que o arcabouço da proteção social brasileiro é generoso. Isto é apontado pelo Banco Mundial (WORD BANK, 2011) fundamentalmente para atacar a não existência de idade mínima, as regras atualmente vigentes para o acesso ao Benefício de Prestação Continuada (BPC) e a vinculação do piso previdenciário ao salário mínimo.

A respeito da questão da idade mínima, Fagnani (2016) aponta que trata-se de um mito utilizado na campanha difamatória contra a Previdência Social, pois, a partir das regras impostas no âmbito da contrarreforma executada pelo governo $\mathrm{FHC}$, estabeleceu-se que a denominada "aposentadoria por idade" seria concedida a mulheres com 60 anos de idade e homens com 65 anos de idade, desde que comprovados o período de quinze anos de contribuição. De acordo com este autor, tal patamar de idade mínima imposto no ano de 1998 era igual ou superior a países com renda per capita maior do que a brasileira, sendo que, naquele ano, a idade mínima de 65 anos não era sequer adotada por países como Canadá, Alemanha e Bélgica, de modo que "[...] transpuseram-se para cá padrões semelhantes e até superiores aos existentes em países desenvolvidos" (FAGNANI, 2016, p. 90).

Quanto às regras do BPC, o economista vulgar adota a retórica de que "[...] a existência de um programa não-contributivo que transfere benefícios equivalentes ao salário mínimo reduz o incentivo para trabalhadores de baixa renda contribuírem para o sistema de proteção social, mas que esperam beneficiarem-se disso na idade tardia" (WORLD BANK, 2011, p. 31). Já foi esclarecido que, na perspectiva da totalidade do ser social, a contribuição previdenciária não decorre de uma escolha, mas está diretamente relacionada à inserção produtiva do trabalhador. Para além desse aspecto, verifica-se que, quando o BM usa o termo "nãocontributivo" refere-se a contribuições diretas, no entanto, o estudo de Salvador (2010) revela o caráter regressivo do sistema tributário no Brasil, tendo em vista a elevada incidência de tributos sobre o consumo, o que onera proporcionalmente os menos favorecidos. Portanto, ao usar o termo "não-contributivo", o BM oculta que os trabalhadores que recebem o BPC também contribuem para a arrecadação do Estado. 
A respeito da vinculação do piso previdenciário ao salário mínimo, o BM (WORD BANK, 2011) tenta deslegitimar esta inter-relação com fins de propor o rebaixamento da magnitude monetária dos benefícios e a intensificação do uso dos programas de transferência de renda mínima, cujos custos são menores. É neste sentido que a agência burguesa afirma que, “[...] indexar o valor do piso previdenciário e sua trajetória talvez não seja o mecanismo mais efetivo para reduzir a pobreza" (WORD BABK, 2011, p. 113).

A partir de dados constantes no Anuário Estatístico da Previdência Social de 2015 (BRASIL, 2015), verifica-se que 54\% dos benefícios ativos do RGPS tinham valor igual ao salário mínimo, enquanto que $23 \%$ compunha a faixa entre 1 e 2 salários mínimos. Isto posto, é relevante atentar para o fato de que, em 2015, o valor do salário mínimo correspondia a $22 \%$ do salário mínimo necessário ${ }^{7}$ apurado pelo Departamento Intersindical de Estatística e Estudos Socioeconômicos (DIEESE) (2017a). A partir desses dados, bem como das informações anteriormente citadas acerca da PNAD, tem-se a seguinte conjuntura acerca do caráter "generoso" da Previdência Social no ano de 2015:54\% dos benefícios previdenciários correspondiam a 22\% do salário mínimo necessário; $77 \%$ tinham valor menor do que a metade do salário apurado para se ter uma vida digna neste país; 38\% da PEA ocupada sequer contribuía para institutos de previdência. Nestas circunstâncias, tem-se elementos para inferir que o argumento do economista vulgar de que o sistema de proteção social brasileiro é generoso é desprovido de valor científico.

Desta maneira, exposto o caráter conservador e liberal das concepções burguesas acerca da Seguridade Social, passa-se à abordagem das relações íntimas entre algumas medidas da contrarreforma e a ética do trabalho assalariado.

\section{RECIPROCIDADE ENTRE A CONTRARREFORMA E A ÉTICA DO TRABALHO ASSALARIADO}

As relações intrínsecas entre a ofensiva contrarreformista à Previdência Social e a ética do trabalho assalariado "livre" serão aqui abordadas por meio do seguinte aspecto: a dialética existente

7 Apuração em dezembro/2015: R\$ 3.518,51. 
entre o aumento do período contributivo e a potencialização do grau de subsunção da classe trabalhadora ao capital, conforme proposição dos economistas vulgares contrarreformistas.

O ponto fulcral da atual etapa da contrarreforma é a proposição de elevar a idade mínima para a aposentadoria, combinada à expansão do tempo de contribuição (DEPARTAMENTO INTERSINDICAL DE ESTATÍSTICA E ESTUDOS SOCIOECONÔMICOS, 2017b). Enquanto no texto original o governo queria impor a idade mínima de 65 anos para homens e mulheres, o Substitutivo aprovado na Comissão Especial da Câmara dos Deputados estabeleceu a idade de 65 anos para homens e 62 anos para as mulheres. Esta regra se fará acompanhada por um gatilho arbitrário, o qual constitui-se em um mecanismo que prevê o aumento automático de um ano na idade mínima a cada vez que a expectativa média de sobrevida aos 65 anos elevar-se em um inteiro.

Como se não bastasse, propõe-se o aumento do período mínimo contributivo, elevando o tempo de carência dos atuais quinze anos para inacreditáveis vinte e cinco anos. De acordo com a análise do Dieese (2017), à luz dos elevados graus de rotatividade e informalidade do mercado de trabalho brasileiro, “[...] esse tempo mínimo de contribuição torna provável que grande número de trabalhadores se encontrem desprotegidos no fim da vida laboral" (DEPARTAMENTO INTERSINDICAL DE ESTATÍSTICAS E ESTUDOS SOCIOECONÔMICOS, 2017b, p. 21). Por seu turno, sob a retótica de que no Brasil aposenta-se cedo, o economista vulgar Banco Mundial revela a natureza burguesa e o objetivo real que reveste tal proposição de "adiamento da aposentadoria", ao afirmar que os "benefícios públicos" desta proposta são os seguintes: "[...] trabalhadores contribuem por mais tempo para o sistema de pensões assim como para a força de trabalho, e consequentemente vão se beneficiar por um menor período de tempo, reduzindo as diferenças entre benefícios e contribuições" (WORLD BANK, 2011, p. 102).

Em uma perspectiva desde a crítica da economia política, esta dimensão primordial da contrarreforma precisa ser analisada a partir do prolongamento do tempo de trabalho da classe oprimida, o que potencializará sua subsunção ao capital. 
No âmbito da teoria social crítica marxiana, a acumulação do capital está assentada na extração de mais-valia, que, por sua vez, tem como pressuposto básico a produção capitalista, a qual somente pode ser concretizada a partir da existência de duas espécies antagônicas de detentores de mercadorias: aqueles que possuem dinheiro, meios de produção e subsistência, que para valorizarem sua soma-valor, compram trabalho alheio; e os trabalhadores livres, desprovidos de meios de produção e vendedores da própria força de trabalho. Nesta seara, o sistema consolida-se a partir da subordinação do trabalho ao capital (MARX, 1983). Para que esta subsunção se concretize, são fundamentais o princípio da ética do trabalho assalariado "livre" e o movimento que Marx (1996) denomina "a chamada acumulação primitiva".

Behring e Boschetti (2011), ao delinearem como os ideais liberais burgueses são inerentemente negatórios da política social, apontam que o princípio do trabalho como mercadoria é um dos sustentáculos desta doutrina, sendo a ética do trabalho uma direção intelectual "[...] que aponta o trabalho em si como atividade edificante e benéfica, sendo seu fruto o progresso, sem considerar as condições em que esse trabalho se realiza" (BEHRING; BOSCHETTI, 2011, p. 60).

Especificamente no caso do capitalismo periférico brasileiro, Ianni (1996) afirma que, desde o declínio do regime escravocrata, iniciouse, no Brasil, um processo de redefinição ideológica do trabalho braçal como forma de libertar a força de trabalho do estigma criado pelo escravagismo e, com isso, converter o trabalho em uma atividade dignificante. Assim, o autor entende que se desenvolveu uma ampla louvação ao trabalho, ou seja, houve no país "[...] uma reiterada apologia do trabalho. Essa é uma pedagogia antiga, contínua e presente. Em todos os lugares, de modo explícito e difuso, no meio do entretenimento e de forma subliminar, sempre está em curso a pedagogia do trabalho" (IANNI, 1996, p. 108). A ética do trabalho assalariado, portanto, é um princípio essencial para o funcionamento do modo de produção capitalista, pois, ao torná-lo dignificante, oculta a relação de exploração que está na essência da valorização do capital.

Porém, a consolidação das relações sociais de produção tipicamente capitalistas que se baseiam na venda da força de trabalho pela 
classe trabalhadora aos detentores dos meios de produção precisa de um outro mecanismo, o qual relaciona-se em fazer com que a única forma de sobrevivência da classe trabalhadora seja, necessariamente, a venda força de trabalho. Ao contrário do que previa a economia política clássica, este processo não foi natural, mas dotado de particularidades socio-históricas, que Marx (1996) denominou a assim chamada acumulação primitiva.

Na concepção marxiana, o processo de acumulação primitiva é precedente à acumulação capitalista e caracteriza-se por momentos em que grandes massas humanas são arrancadas de forma súbita e violenta de seus meios de subsistência e são lançadas no mercado de trabalho como "[...] proletários livres como os pássaros" (MARX, 1996, p. 341-342). Para tanto, foi fundamental, por um lado, a transformação dos meios sociais de subsistência e dos meios sociais de produção em capital e, por outro lado, os produtores diretos precisaram ser convertidos em trabalhadores assalariados. Trata-se, ao fim e ao cabo, de um movimento histórico que promoveu o lançamento de grandiosas massas humanas no mercado de trabalho.

Ao analisar o capital-imperialismo na cena contemporânea, Fontes (2010) identifica a promoção de expropriações secundárias que, em escala e magnitude, estão incidindo de forma ameaçadora sobre as condições de vida e trabalho. As expropriações não se dão apenas em sua forma marxiana original, isto é, no âmbito da terra e da detenção dos meios sociais de produção, mas se estendem aos segmentos urbanos, conformando um novo contexto de massivas disponibilizações dos trabalhadores para o mercado (FONTES, 2010).

Como exemplo prático desse movimento de expropriação no âmbito da política de Previdência, Fontes (2010) faz referência ao contexto de elevação das idades mínimas para a aposentadoria nos países do centro e da periferia do capital. Assim, a tendência de elevação das idades mínimas para acesso ao benefício previdenciário constitui-se em uma das formas contemporâneas de expropriação, consolidando o movimento denominado produção massiva de seres sociais disponibilizados (FONTES, 2010).

Portanto, à luz desta fundamentação teórica, pode-se conceber como a elevação da idade mínima e o aumento do tempo de 
contribuição exigidos para o acesso aos benefícios previdenciários terão o condão de disponibilizar o trabalhador "livre" à subsunção ao capital, o que culminará em um prolongamento do tempo em que ocorrerá a venda de sua força de trabalho e o encurtamento se lá conseguir chegar - do período de percepção da aposentadoria. É, pois, desta maneira que a contrarreforma possui uma relação íntima com a ética do trabalho assalariado "livre".

\section{CONSIDERAÇÕES FINAIS}

Este artigo teve como objetivo geral fornecer elementos para uma crítica marxista à economia política da contrarreforma da Previdência Social no Brasil e como objetivo específico desvendar o caráter liberal que permeia os pressupostos, os argumentos e algumas das propostas que compõem tal ofensiva.

De modo geral, confirmou-se a hipótese de que a marcha contrarreformista está revestida por uma visão social de mundo burguesa propagada por economistas vulgares cujo maior expoente é o Banco Mundial, e que, por meio de argumentos desprovidos de valor científico, oculta-se substância de todo o processo: a necessidade de potencializar o grau de subsunção da classe produtora do valor ao capital.

Em última instância, essa conjuntura expressa um contexto de visceral agudização da luta de classes em um modo de produção que deteriora-se a passos largos generalizando a barbarização das condições de trabalho e proteção social no centro e na periferia do capitalismo. Mais ainda, a crítica marxista aqui realizada desnuda a relevância científica deste campo teórico e de suas categorias ontológicas para a análise e desmistificação desta quadra histórica, de maneira que esta cientificidade deve ser direcionada às lutas pela verdadeira transformação desta realidade, afinal "[...] os filósofos se limitaram a interpretar o mundo de diferentes maneiras; mas o que importa é transformá-lo" (MARX; ENGELS, 2007, p. 117).

\section{REFERÊNCIAS}

ASSOCIAÇÃO NACIONAL DOS AUDITORES-FISCAIS DA RECEITA FEDERAL DO BRASIL; FUNDAÇÃO ANFIP DE ESTUDOS DA SEGURIDADE SOCIAL. Análise da Seguridade Social 2015. 16. ed. Brasília (DF), 2016. Disponível em: <https://www.anfip.org. 
br/doc/publicacoes/20161013104353_Analise-da-SeguridadeSocial-2015_13-10-2016_Anlise-Seguridade-2015.pdf>. Acesso em: 28 set. 2017.

BANCO MUNDIAL. Envejecimiento sin crisis: políticas para la protección de los ancianos y la promoción del crecimiento. Washington D.C., 1994.

BEHRING, E. Brasil em contra-reforma: desestruturação do Estado e perda de direitos. 2. ed. 3. reimpr. São Paulo: Cortez, 2008.

BEHRING, E.; BOSCHETTI, I. Política social: fundamentos e história. 9. ed. 6. reimp. São Paulo: Cortez, 2011.

BOSCHETTI, I. Assistência social e trabalho no capitalismo. São Paulo: Cortez, 2016.

BRASIL. Ministério da Fazenda. Anuário Estatístico da Previdência Social. AEPS 2015. Brasília (DF): MF/DATAPREV, 2015. v. 24. Disponível em: <http://www.previdencia.gov.br/wp-content/ uploads/2015/08/AEPS-2015-FINAL.pdf>. Acesso em: 28 set. 2017.

BRASIL. Proposta de Emenda à Constituição n 287 de 2016. Altera os arts. 37, 40, 109, 149, 167, 195, 201 e 203 da Constituição, para dispor sobre a seguridade social, estabelece regras de transição e dá outras providências. Brasília (DF), 2016. Disponível em: <http://www.camara.gov.br/proposicoesWeb/prop_mostrari ntegra;jsessionid $=5$ BC988856C5651E8FBA39DE210E3B4CF.propo sicoesWebExterno2? codteor $=1514975$ \&filename $=P E C+287 / 2016>$. Acesso em: 28 set. 2017.

COUTINHO, C. N. A hegemonia da pequena política. In: BRAGA, R., et al. (Orgs.). Hegemonia às avessas. São Paulo: Boitempo, 2010. pp. 29-43.

DEPARTAMENTO INTERSINDICAL DE ESTATÍSTICA E ESTUDOS SOCIOECONÔMICOS. Salário mínimo nominal e necessário. Apuração em dezembro/2015: R\$ 3.518,51. São Paulo, $2017 a$. Disponível em: <https://www.dieese.org.br/analisecestabasica/ salarioMinimo.html>. Acesso em: 26 set. 2017.

DEPARTAMENTO INTERSINDICAL DE ESTATÍSTICAS E ESTUDOS SOCIOECONÔMICOS. PEC 287-A: A reforma da Previdência 
e da Assistência Social na versão aprovada pela Comissão Especial da Câmara dos Deputados. São Paulo, jul. 2017a. (Nota Técnica $n^{\circ}$ 186). Disponível em: <https://www.dieese.org.br/ notatecnica/2017/notaTec287Substitutivo.html>. Acesso em: 28 set. 2017.

FAGNANI, E. Apresentação. In: PUTY, C. A. C. B.; GENTIL, D. L. G. (Orgs.). A Previdência Social em 2060: as inconsistências do modelo de projeção atuarial do governo brasileiro. Brasília (DF): ASSOCIAÇÃO NACIONAL DOS AUDITORES-FISCAIS DA RECEITA FEDERAL DO BRASIL, 2017. Disponível em: <https://www.dieese. org.br/evento/2017/aPrevidenciaSocialEm2016.pdf>. Acesso em: 28 set. 2017.

FAGNANI, E. Previdência social: reformar ou destruir? In: SINGER, André et al. Por que gritamos golpe?: para entender o impeachment e a crise política no Brasil. São Paulo: Boitempo, 2016.

FONTES, V. O Brasil e o Capital-Imperialismo: teoria e história. Rio de Janeiro: Fundação Oswaldo Cruz; Universidade Federal do Rio de Janeiro, 2010.

GRANEMANN, S. PEC 287/16: falácias para a desconstrução dos direitos do trabalho. SER Social, Brasília (DF), v. 18, n. 39, p. 672688, 2. sem./2016. Disponível em: <http://periodicos.unb.br/index. php/SER_Social/article/view/24469/17551>. Acesso em: 28 set. 2017.

GRANEMANN, S. Para uma interpretação marxista da "previdência privada". 2006. (Tese de Doutorado de Serviço Social) da Escola de Serviço Social da Universidade Federal do Rio de Janeiro, 2006.

IANNI, O. A questão social. In: IANNI, O. A ideia de Brasil moderno. São Paulo: Brasiliense, 1996.

INSTITUTO BRASILEIRO DE GEOGRAFIA E ESTATíSTICA. Pesquisa Nacional por Amostra de Domicílios. Síntese de indicadores 2015. Rio de Janeiro: IBGE. 2016. 108p.

LOWY, M. Ideologias e ciência social: elementos para uma análise marxista. 20. ed. São Paulo: Cortez, 2015. 
MARX, K; ENGELS, F. A ideologia alemã: Feuerbach: A contraposição entre as cosmovisões materialista e idealista. Trad. Frank Muller. São Paulo: Editora Martin Claret. 2007.145p.

MARX, K. Contribuição à crítica da economia política. 2. ed. São Paulo: Expressão Popular, 2008. 288p.

MARX, K. O Capital. A Assim Chamada Acumulação Primitiva. In: MARX, K. O Capital: Crítica da Economia Política. Volume I. Livro Primeiro. Tomo 2. Editora Nova Cultural: São Paulo. 1996. pp. 338381.

MARX, K. O capital: Crítica da economia política. Volume I. Livro Primeiro. Tomo 1. São Paulo: Abril Cultural, 1983.

PAIVA, S. O. C. Envelhecimento, saúde e trabalho no tempo do capital. 1. ed. São Paulo: Cortez, 2014.

PAULANI, L. M. Neoliberalismo e Individualismo. Economia e Sociedade, Campinas, n. 13, p. 115-127, dez. 1999. Disponível em: <https://periodicos.sbu.unicamp.br/ojs/index.php/ecos/article/ view/8643138/10688>. Acesso em: 28 set. 2017.

PEREIRA, J. M. M. (Org.). A demolição de direitos: um exame das políticas do Banco Mundial para a educação e a saúde (1980-2013). Rio de Janeiro: Escola Politécnica de Saúde Joaquim Venâncio, 2014. Disponível em: <http://www.epsjv.fiocruz.br/sites/default/ files/l240.pdf>. Acesso em: 25 set. 2017.

SALVADOR, E. Fundo público e seguridade social no Brasil. São Paulo: Cortez, 2010.

SILVA, M. L. L. Previdência social no Brasil: (des) estruturação do trabalho e condições para sua universalização. São Paulo: Cortez, 2012.

WORLD BANK. Growing old in an older Brazil: implications of population aging on growth, poverty, public finance and service delivery. Washington D.C., 2011. 